American Journal of Applied Sciences 3 (6): 1890-1893, 2006

ISSN 1546-9239

(C) 2006 Science Publications

\title{
Design of Active Integrated Antenna for Dual Frequency Image Rejection
}

\author{
${ }^{1}$ Sohiful Anuar Zainol Murad and ${ }^{2}$ Widad Ismail \\ ${ }^{1}$ School of Microelectronic Engineering, Northern Malaysia University College of Engineering, \\ Kompleks Pusat Pengajian KUKUM, 02600 Jejawi, Perlis, Malaysia \\ ${ }^{2}$ School of Electrical and Electronic Engineering, USM Engineering Campus, \\ University Science of Malaysia, 14300 Nibung Tebal, Seberang Prai Selatan, Penang, Malaysia
}

\begin{abstract}
This paper is discusses a new configuration of integrated antenna for dual frequency operations and image frequency rejection. Microstrip patch antenna is design in such away to operate in dual frequencies band. The RF $90^{\circ}$ hybrid, LNA's, mixers, LO and IF coupler are integrated to a dual frequency microstrip patch antenna to produce a single module of integrated antenna system that can perform for in dual-band frequencies. The design technique and simulation result for active integrated antenna (AIA) with image rejection is presented.
\end{abstract}

Key words: Microstrip patch antenna, dual-band frequencies, design technique, simulation

\section{INTRODUCTION}

Nowadays, microwave antennas have been widely used especially in achieving the objective of maximal integration for personal communication system. These antennas can be mounted on the surface of high performance aircrafts, satellites, missiles, mobile phones and others.

Integrated antennas are a combination of solid-state devices and circuits with printed antenna structures and comprise of integrated radio system elements that are fabricated using inexpensive printed circuit techniques $^{[1]}$. The area of integrated antennas has become an important area of research because it can give excellent results in term of efficiency, compactness, lightweight and low cost compared to the conventional systems. The main disadvantage of microstrip antenna is an intrinsic limitation in bandwidth, which is due to the resonant nature of the patch structure $\left.{ }^{[2}\right]$. This problem gives a new motivation for research on solutions to overcome the bandwidth limitations of the microstrip antenna. Therefore, for applications that need to increase the bandwidth for operating at two separate sub-bands is represented by dual-frequency microstrip antenna ${ }^{[3,4]}$. This antenna can be more useful for system that can receive and transmit at the same time.

Image reject is the process whereby the image to the RF signals is channelized into two different ports using phase cancellation technique ${ }^{[5]}$. It is useful in reducing the cost and complexity due to expensive preselection for the front-end receiver. Therefore, this paper introduces an image reject system that can operate for dual frequency.
Proposed DFIA image reject mixer (IRM) system: The first active integrated antenna (AIA) with image rejection has been introduced by Maci and Gentili ${ }^{[6]}$. The proposed configuration is similar to that but with the phase shift rearranged and useful for dual frequency operation. The image reject mixer (IRM) comprises of two-balanced mixer of any topology driven in quadrature by the amplified radio frequency (RF) signal. The LO leads an in-phase power divider that drives each mixer and the IF output power is combined in quadrature. Figure 1 shows the block diagram of the proposed IRM system.

In principle, dual frequency patch antenna should operate with similar features in both term of radiation and impedance matching at two separate frequencies. There are many techniques to obtain dual frequency patch antenna, such as orthogonal-mode, multi layer patch and reactively loaded. Maci and Gentili ${ }^{[2]}$ introduces many of these techniques where one of the techniques is used in the system. A single layer slotted square patch antenna is used to provide the dual frequency operation. Using two pairs of orthogonal slots as shown in Fig. 1 produces the dual frequency antenna.

Design methods: A square patch antenna of length and width of $35 \mathrm{~mm}$ is designed using FR4 with dielectric constant of 4.5 , height of $1.6 \mathrm{~mm}$. The slots length is 29 $\mathrm{mm}$ and the width is $1 \mathrm{~mm}$. The slots are $1 \mathrm{~mm}$ away from the patch edges. The square patch antenna is simulated using Advanced Design System (ADS) momentum analysis software from Hewlett Packard Company. The simulation result shows that the square patch antenna designed can perform dual band frequencies at $2.031 \mathrm{GHz}$ with return loss around-

Corresponding Author: Sohiful Anuar Zainol Murad, School of Microelectronic Engineering, Northern Malaysia University College of Engineering, Kompleks Pusat Pengajian KUKUM, 02600 Jejawi, Perlis, Malaysia, Tel: 604-979 8432, Fax: 604-979 8305 


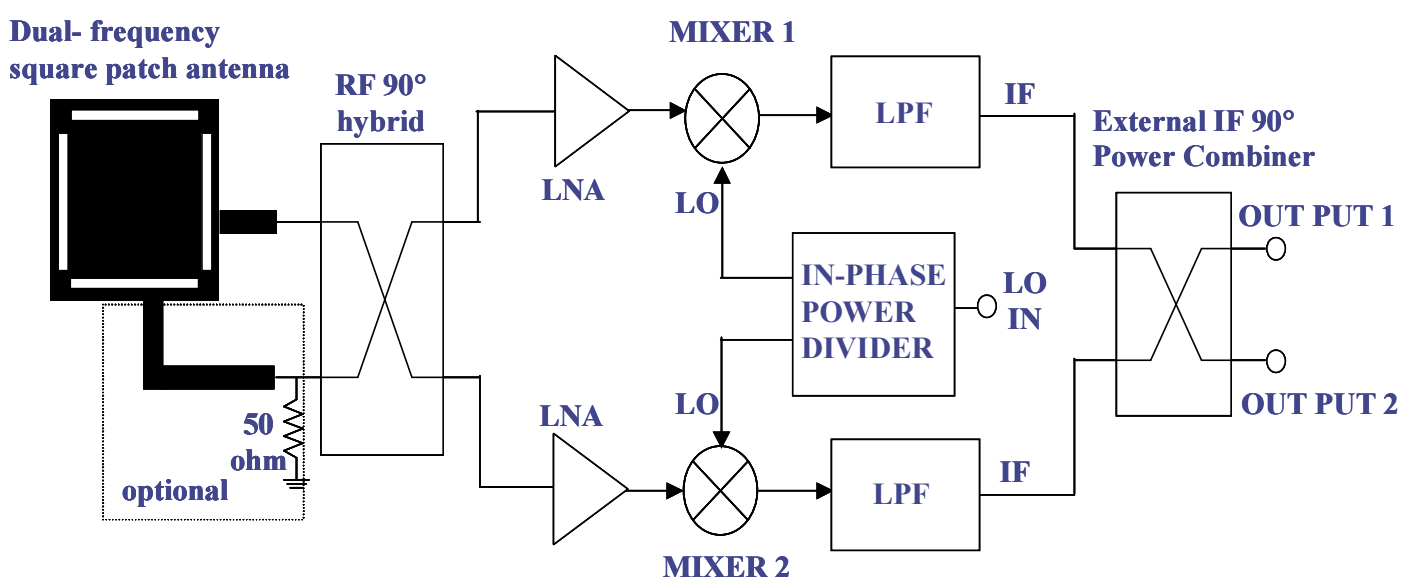

Fig. 1: The proposed architecture of the DFIA with image rejection

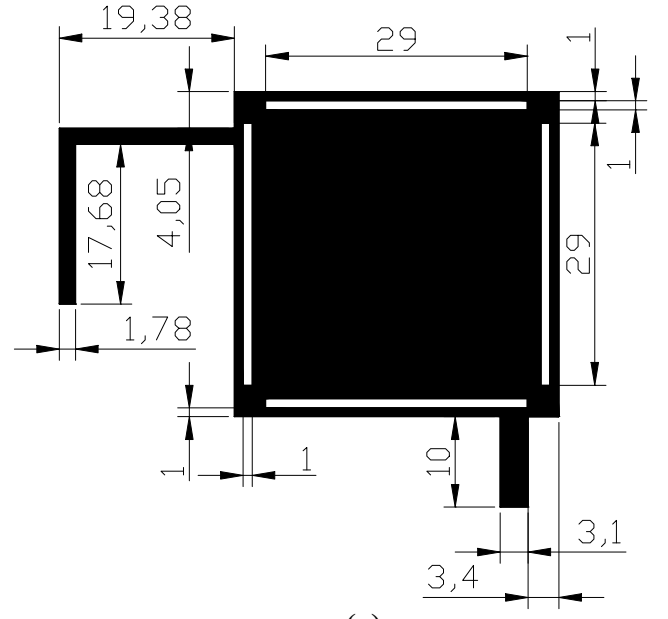

(a)

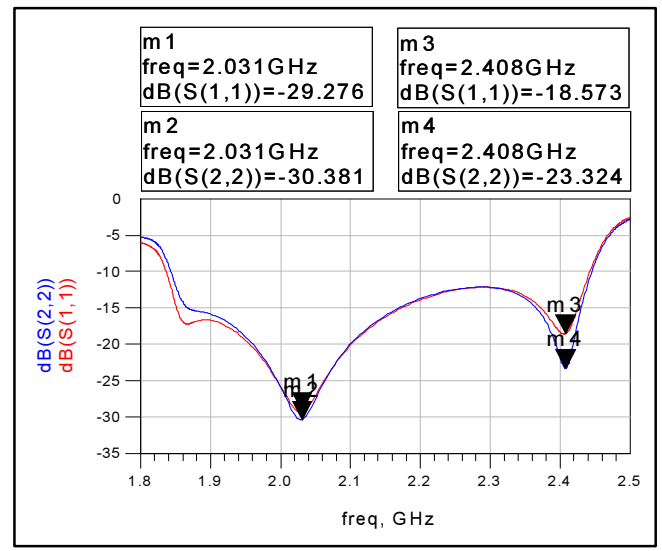

(b)

Fig. 2: (a) Layout of dual frequency square patch antenna (unit in $\mathrm{mm}$ ), (b) Return loss simulation result

Table 1: The simulation result summary

\begin{tabular}{llllll}
\hline RF frequency & LO frequency & Output at Port 1 & Output at Port 2 & Image reject & CL \\
\hline $1.961 \mathrm{GHz}$ & $2.031 \mathrm{GHz}$ & $-18.346 \mathrm{~dB}$ & $-7.434 \mathrm{~dB}$ & $10.91 \mathrm{~dB}$ & $-7.434 \mathrm{~dB}$ \\
$2.101 \mathrm{GHz}$ & $2.031 \mathrm{GHz}$ & $-7.424 \mathrm{~dB}$ & $-18.576 \mathrm{~dB}$ & $11.15 \mathrm{~dB}$ & $-7.424 \mathrm{~dB}$ \\
$2.338 \mathrm{GHz}$ & $2.408 \mathrm{GHz}$ & $-8.054 \mathrm{~dB}$ & $-16.818 \mathrm{~dB}$ & $8.054 \mathrm{~dB}$ & $-8.054 \mathrm{~dB}$ \\
$2.478 \mathrm{GHz}$ & $2.408 \mathrm{GHz}$ & $-19.151 \mathrm{~dB}$ & $-8.371 \mathrm{~dB}$ & $10.78 \mathrm{~dB}$ & $-8.371 \mathrm{~dB}$ \\
\hline
\end{tabular}

$29.28 \mathrm{~dB}$ and $2.408 \mathrm{GHz}$ with a return loss of about$23.32 \mathrm{~dB}$ as shown in Fig. 2.

MGA-83563 Low Noise Amplifier from Agilent Technology is used to boost the received signal because of the high gain provided which is around $22 \mathrm{~dB}$ (from $0.5 \mathrm{GHz}$ to $6 \mathrm{GHz}$ ). A balanced resistive FET mixer is designed using Agilent ATF-34143. The mixer operates at $0 \mathrm{DC}$ bias at the drain and only need the gate to be biased while the source is grounded. A $90^{\circ}$ hybrid coupler is used to combine the two IF output at 70 MHz. The square patch antenna is connected to the LNA and IRM through via hole to complete circuit of the DFIA with image rejection as shown in Fig. 3. The system is simulated using ADS Harmonic Balance circuit simulator.

\section{RESULTS}

The local oscillator (LO) is fixed at $2.031 \mathrm{GHz}$ at the first frequency. From the simulation result shown in Fig. 4, the wanted and the image signal are channelized to different ports. The total image rejection of the lower side band (LSB) is the difference in power of the IF output at RF frequency of $1.961 \mathrm{GHz}$ between port 1 and port 2. The same method is used to find the image rejection for upper side band (USB) at RF frequency $2.101 \mathrm{GHz}$. Therefore, the image rejection at port 2 for LSB is $10.91 \mathrm{~dB}(-7.434 \mathrm{~dB}-(-18.346 \mathrm{~dB}))$ and the image reject at port 1 for USB is $11.15 \mathrm{~dB}(-7.424 \mathrm{~dB}-$ $(-18.576 \mathrm{~dB})$. 


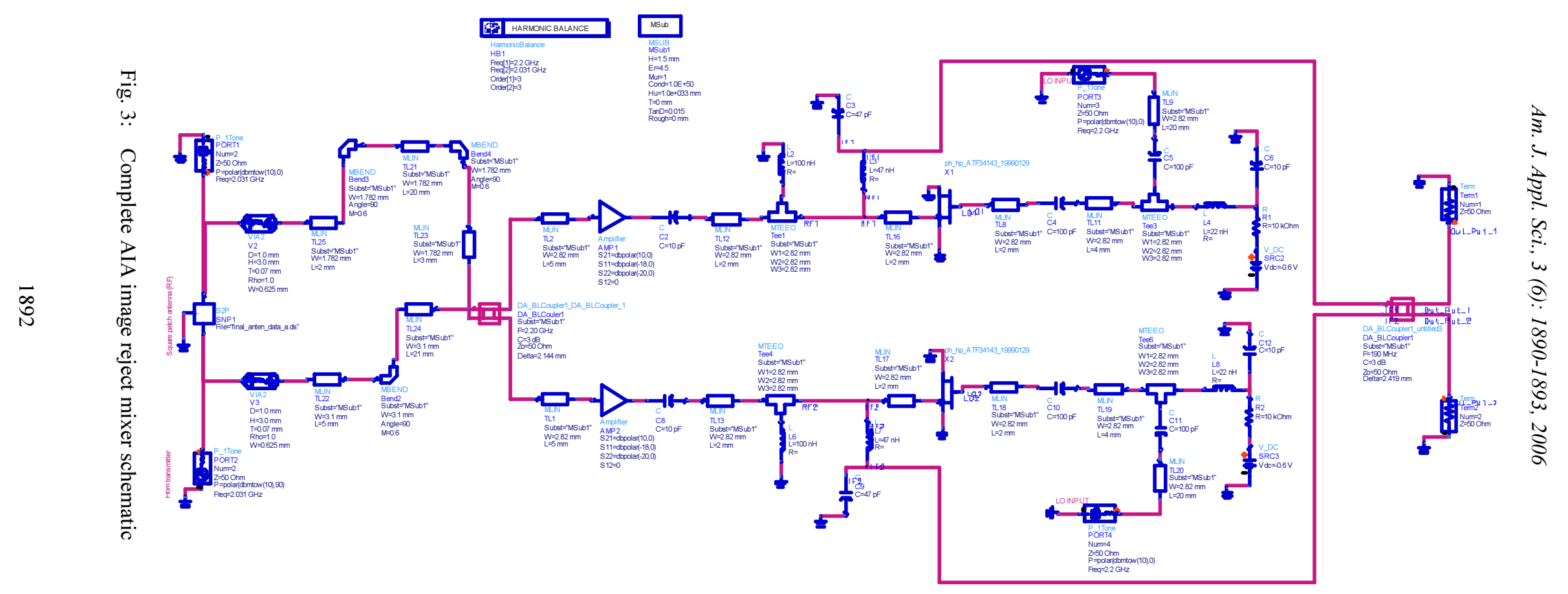




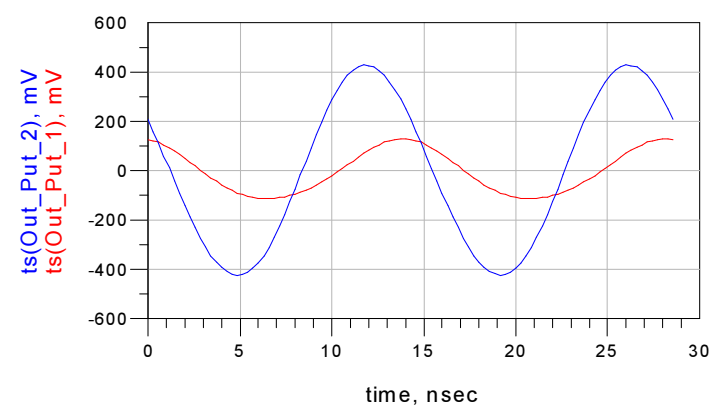

(a)

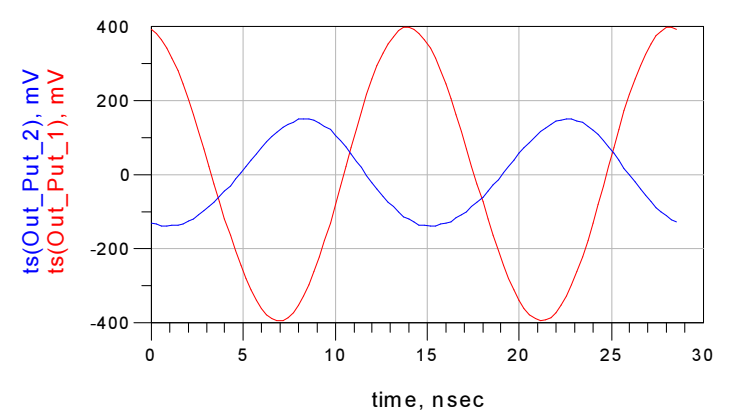

(c)

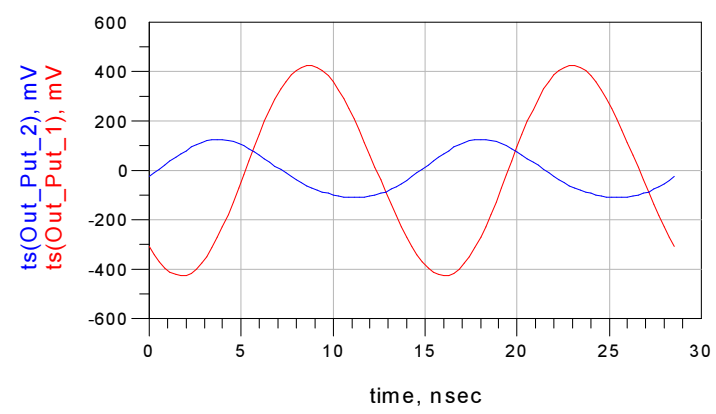

(b)

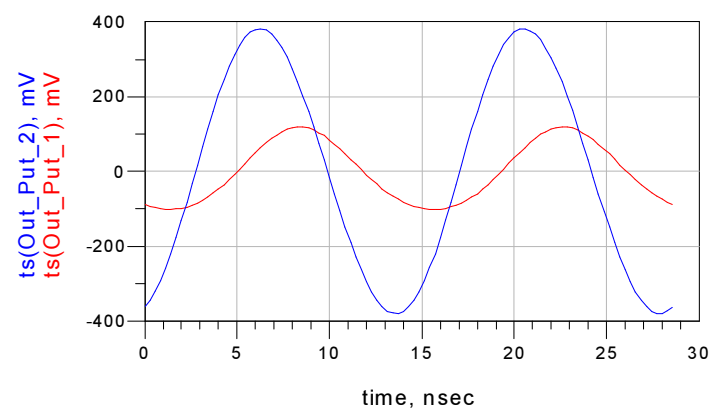

(d)

Fig. 4: The IF signal showing the image rejection at output port IF power combiner. (a) RF frequency at 1.961 $\mathrm{GHz}$ and LO frequency at $2.031 \mathrm{GHz}$. (b) RF frequency at $2.101 \mathrm{GHz}$ and LO frequency at $2.013 \mathrm{GHz}$. (c) RF frequency at $2.338 \mathrm{GHz}$ and LO frequency at $2.408 \mathrm{GHz}$ (d) RF frequency at $2.478 \mathrm{GHz}$ and LO frequency at $2.408 \mathrm{GHz}$

The conversion loss (CL) can be found using equation (1) below.

$\mathrm{CL}=\mathrm{IF}$ output power - Patch antenna receiver power LNA gain (1)

From the parameter setup in Fig. 3, passive antenna receiver power is $-10 \mathrm{~dB}$ and LNA gain is $10 \mathrm{~dB}$. Therefore, by using equation (1), the conversion loss is calculated as follows:

$\mathrm{CL}$ at Port $2=-7.434-(-10)-10=-7.434 \mathrm{~dB}$

CL at Port $1=-7.424-(-10)-10=-7.424 \mathrm{~dB}$

All the results can be summary in Table 1 below.

\section{DISCUSSION}

The simulation result show that the square patch antenna designed can perform dual band frequencies. The patch antenna needs to be combined with RF $90^{\circ}$ hybrid to perform $90^{\circ}$ phase difference between two RF signals that will be used in the proposed IRM system. Using phase calculation techniques, image rejection can be achieved as shown from the simulation results. Phase cancellations are performed with image rejection of around $10 \mathrm{~dB}$. Therefore, this architecture introduces a new technique in up/down-conversion and modulation, thus it is suitable as a transmitter and receiver at the same time that can support more than one wireless standard through the use of the dual frequency operations.

\section{ACKNOWLEDGEMENT}

The authors would like to thanks KUKUM for the financial support for completing this project. The authors would also like to thanks to those who have contributed either directly or indirectly for this project.

\section{REFERENCES}

1. Carl, W.P. and T. Itoh, 1997. Active Integrated Antennas. IEEE Potentials.

2. Maci, S. and B. Gentili, 1997. Dual-frequency patch antenna. IEEE Antennas and Propagation Magazine, 39: 6.

3. Tseng, H.-W., R. Kurtz, A. Brown, D. Nathans and F. Pahr, 2002. Test results of a dual frequency (L1/L2) small controlled reception pattern antenna. Proc. ION NTM 2002, San Diego, CA.

4. Jen-Yea Jan, 2003. Single-layer single-feed dualfrequency circular microstrip antenna with an offset open-ring slot. IEEE Trans. Antennas and Propagation, 51: 3010-3012.

5. Bert, C.H. and J.A. Cook, Image Reject and Single-Sideband Mixers. Technical Note from WJ Communication Inc, www.wj.com

6. Maci, S. and B. Gentili, Dual-frequency patch antennas. IEEE Antennas and Propagation Magazine, 39: 6. 